\title{
FINDINGS, THEORIES AND METHODS IN THE STUDY OF CHILDREN'S NATIONAL IDENTIFICATIONS AND NATIONAL ATTITUDES
}

\author{
Martyn Barrett ${ }^{1}$ and Louis Oppenheimer ${ }^{2}$ \\ ${ }^{1}$ Department of Psychology, University of Surrey, UK, \\ 2 Department of Developmental Psychology, University of Amsterdam, NL
}

\begin{abstract}
This paper reviews some of the relevant background findings against which the empirical studies reported in this special issue were designed. Particular attention is given to previous findings on the development of children's national knowledge, national attitudes and national identifications. The paper also reviews five existing theories which have been proposed to explain the development of children's intergroup attitudes: cognitive-developmental theory (Aboud, 1988, 2008), social identity development theory (Nesdale, 2004, 2008), social identity theory (Tajfel, 1978; Tajfel \& Turner, 1986), societal-social-cognitive-motivational theory (Barrett, 2007, 2009; Barrett \& Davis, 2008) and integrative developmental-contextual theory (Bar-Tal \& Teichman, 2005; Teichman \& Bar-Tal, 2008). The paper concludes by describing the shared methodology which was utilised by all of the following studies that are reported in this special issue. These studies were designed to examine how children's attitudes to other nations develop within a range of different national contexts, some of which have not experienced violent conflict in the recent past (England, The Netherlands) but others of which have recently experienced, or still are experiencing, conflict, violence or warfare (Basque Country, Bosnia, North and South Cyprus, Northern Ireland, Israel).
\end{abstract}


This special issue of the European Journal of Developmental Psychology is devoted to a series of studies that have emerged from a multinational research project which investigated children's national identifications and attitudes to national ingroups and outgroups as determinants of the understanding of enemy and the presence of enemy images (Barrett, 2007; Oppenheimer, 2005, 2006). One of the distinctive features of this project is that data were collected in a range of different national contexts, some of which have not experienced violent conflict in the recent past (England and The Netherlands) but others of which have recently experienced, or still are experiencing, conflict, violence or warfare (Basque Country, Bosnia, North and South Cyprus, Northern Ireland and Israel). In total, children from 12 national groups participated, including Jewish and Arab children (Israel), Bosniak and Serbian children (Bosnia), Catholic and Protestant children (Northern Ireland), Greek-Cypriot and Turkish-Cypriot children (Cyprus), Basque and Spanish children (the Basque Country), and Dutch and English children (The Netherlands and England).[1] The project was based on the assumption that children's national identifications and attitudes are related to the everyday patterns of discourse and practices that occur within the particular socio-historical settings in which they are living, and for this reason the contrast in the development of children growing up within relatively peaceful vs. conflict-ridden contexts was expected to be particularly marked.

In this paper, we describe some of the relevant background findings and theories in the field, so that readers are able to situate the present work within its broader research context. This paper also describes the shared methodology which was employed by all of the studies reported in this special issue.

\section{Previous findings on children's national knowledge, national attitudes and national identifications}

Studies exploring children's geographical knowledge of their own country have typically found that such knowledge begins to be acquired from about 5 years of age (Barrett, 2005a, 2007; Jahoda, 1963a; Piaget \& Weil, 1951), with the mass media (especially television) and travel being important sources of information (Gould \& White, 1986). Children's geographical knowledge of other countries starts to develop at a slightly later age, with a significant increase in such knowledge occurring at about 8 years (Barrett, 1996; Jahoda, 1962; Wiegand, 1991a). Children's geographical knowledge of other countries is largely derived from foreign travel, formal teaching at school and television and films, and varies as a function of their social class, nationality, ethnicity and geographical location (Axia, Bremner, Deluca \& Andreason, 1998; Bourchier, Barrett \& Lyons, 2002; Holloway \& Valentine, 2000; Wiegand, 1991a, 1991b).

Most children already know some of the symbolic emblems (e.g., flags, national anthems, etc.) which are used to represent their own country by 5-6 years of age, and this emblematic knowledge continues to develop over subsequent years (Barrett, 2007; Helwig \& Prencipe, 1999; Jahoda, 1963b; Moore, Lare \& Wagner, 1985; Weinstein, 1957). There is significant crossnational variability in such knowledge (Barrett et al., 1997), and there are also variations within countries in children's use of, and affect for, national emblems as a function of their language group, ethnicity and gender (Moodie, 1980; Moore et al., 1985).

Other studies which have investigated the development of children's national stereotypes have shown that stereotypes of some groups are acquired already by the age of 5 or 6 (Barrett \& Short, 1992; Barrett, Wilson \& Lyons, 2003; Bar-Tal, 1996; Lambert \& Klineberg, 1967; Oppenheimer \& Hakvoort, 2003), with these stereotypes gradually being elaborated over the next few years so that, by 10 or 11 years, children hold extensive beliefs about the typical physical 
features, clothing, habits, psychological and personality traits of a large number of different national groups. Children obtain their beliefs about other national groups from many different sources, including television, films, books, school work, teachers, parents, visits to other countries, and personal contact with foreigners (Barrett, 2007; Barrett \& Short, 1992; Bar-Tal, 1997; Holloway \& Valentine, 2000; Lambert \& Klineberg, 1967).

Schools, in particular, usually provide a great deal of explicit teaching to children about their own nation via the curriculum in subjects such as history, geography, civic/citizenship education, language and literature. It is therefore especially noteworthy that school curricula and textbooks in these subjects frequently contain ethnocentric biases, with the child's own nation usually being presented in a highly positive light compared with other nations (Apple, 1993; Schleicher \& Kozma, 1992).

Children's attitudes to and feelings about other nations are often idiosyncratic before about 7 years of age. However, an exception occurs in the case of those nations which are the 'traditional enemies' of the child's own country, which are often disliked from an earlier age (Barrett, 2007; Jahoda, 1962; Oppenheimer \& Hakvoort, 2003; Piaget \& Weil, 1951; Teichman, 2001). Indeed, in countries which have experienced warfare, extreme negativity may be displayed towards enemy groups as early as 2 or 3 years of age (Bar-Tal, 1996; Bar-Tal \& Teichman, 2005; Povrzanovi?, 1997). From 7 years onwards, many children exhibit a preference for their own country and national group over all others, and express strong national pride, with ingroup preference and national pride sometimes strengthening still further through middle childhood (Barrett \& Short, 1992; Hess \& Torney, 1967; Johnson, Middelton \& Tajfel, 1970; Jaspers, van de Geer, Tajfel \& Johnson, 1972). However, some other countries and national groups may still be very positively liked and, in a few cases, may even be preferred over the child's own country or national group (Middleton, Tajfel \& Johnson, 1970; Moore et al., 1985; Tajfel, Jahoda, Nemeth, Rim \& Johnson, 1972). Hence, contrary to popular notions, ingroup favouritism and outgroup denigration are not universal phenomena in this domain.

In addition, children's attitudes towards national groups display considerable variation in how they develop through middle childhood. For example, with increasing age, children's national attitudes sometimes become more positive, sometimes more negative, sometimes more negative before becoming more positive again, sometimes more positive before becoming more negative again, and sometimes children's national attitudes do not show any changes at all across middle childhood (Barrett, 2007; Lambert \& Klineberg, 1967). Furthermore, different developmental profiles may be exhibited depending on the particular national outgroup involved. These differential patterns seem to be related to a number of factors, including the perceived characteristics of the target group involved, the national context within which the child is growing up, and the child's own specific geographical, ethnic and linguistic position within that national context (Barrett, 2007).

As far as children's national identifications are concerned, by the age of 6 , most children do usually acknowledge their membership of their own national group, but their strength of subjective identification with that group varies at this early age (Barrett, 2007). There is also a great deal of variation in the subsequent development of children's national identifications. This variation seems to depend on the specific country in which the child lives, the child's geographical location within that country, the child's ethnicity, the use of language in the family home, and the child's language of schooling (Barrett, 2005b, 2007). The strength of national identification is usually correlated with the child's general affect towards the national ingroup (Barrett, 2007; Barrett, Lyons \& del Valle, 2004). However, the strength of national identification 
is only sometimes related to the positive distinctiveness which is attributed to the ingroup over outgroups as measured using trait attribution tasks (Barrett, 2007).

\section{Theoretical accounts of the development of intergroup attitudes in childhood}

Several theoretical accounts have been proposed to explain the development of children's intergroup attitudes. Here, we focus on the five theories which are the most pertinent to the studies on children's national attitudes reported in this special issue.

Cognitive-developmental theory. Cognitive-developmental theory (CDT) has been primarily expounded and elaborated by Aboud (1988, 2008; Aboud \& Amato, 2001; Doyle \& Aboud, 1995; Doyle, Beaudet \& Aboud, 1988). She argues that children's intergroup attitudes are driven by their underlying cognitive and socio-cognitive development. Strongly Piagetian in orientation, CDT postulates that there is a watershed in the development of children's intergroup attitudes at the age of about 6-7 years. Prior to this age, Aboud suggests, children's egocentricity and affective processes dominate their responses to people from other national, ethnic and racial groups, with the result that they exhibit pronounced ingroup bias and negative prejudice against outgroups. These biases are hypothesised to peak at 6-7 years, after which they decline. Aboud argues that, at 6-7 years, children attribute mainly positive traits to their own ingroup and mainly negative traits to outgroups; however, between 6-7 and 11-12 years, children increasingly attribute more negative traits to the ingroup and more positive traits to outgroups. This results in a reduction in levels of both ingroup bias and outgroup prejudice. These shifts are hypothesised to be driven by the development of the child's underlying cognitive and socio-cognitive skills.

In her more recent formulations, Aboud (2008; Aboud \& Amato, 2001) has acknowledged that socialization factors may sometimes influence children's intergroup attitudes, particularly those of ethnic minority children who do not always exhibit outgroup prejudice before 6-7 years. However, she argues that the effectiveness of parental discourse, media representations and educational input in altering children's attitudes depends on the child's cognitive mindset, with children's own cognitive abilities determining which social inputs are influential.

Because of its postulation of a single normative pattern of development grounded in a universal sequence of cognitive-developmental changes, CDT has difficulty in explaining the sheer variety of different developmental patterns which children's attitudes to national groups display during middle childhood (Barrett, 2007; Lambert \& Klineberg, 1967). Aboud and Amato (2001, p.78) themselves also acknowledge that CDT lacks a clear explanation of why children differentiate between outgroups, attaching positive evaluations to some outgroups and negative evaluations to others.

Social identity development theory. In recent years, social identity development theory (SIDT) has been put forward by Nesdale $(2004,2008)$ as an alternative to CDT, and the theory does indeed make very different predictions from CDT. SIDT postulates that there are four phases in the development of children's intergroup attitudes. Before 2-3 years of age, cues about people's racial, ethnic and national group memberships are not yet salient to the child. The second phase starts at about 3 years, when awareness of these cues begins to emerge. In addition, during this second phase, the child acquires the awareness that he or she is a member of the ingroup. SIDT postulates that, during the third phase, which commences at about 4 years, the child focuses on, and prefers, the ingroup over outgroups. During this phase, the child does not dislike or reject outgroups. Instead, the ingroup is merely preferred over other groups. The fourth phase of development postulated by SIDT begins at about 7 years, when the child's focus shifts away from the ingroup and towards outgroups and negative prejudice against outgroups begins to emerge. 
However, Nesdale argues that not all children enter this final phase. Whether they do so depends on whether the child internalises prejudices current amongst members of the ingroup. The likelihood of this occurring is driven by the strength of the child's subjective identification with the ingroup, how widespread the negative attitudes are among members of the ingroup, and the extent to which ingroup members feel under threat from the outgroup concerned. SIDT therefore predicts that negative prejudice against 'enemy' nations will arise after the age of 7 in those countries which perceive themselves to be under threat from other nations and where negative attitudes to the 'enemy' nations are widely held by ingroup members.

CDT and SIDT are polarised in the predictions which they make about the development of prejudice, with CDT proposing that outgroup prejudice increases up to 6-7 years and then decreases, and with SIDT proposing that it is only after 7 years that prejudice starts to develop (and even then may not develop in all children). CDT has drawn much of its evidence from studies which have used trait attribution tasks to test children's explicit attitudes towards groups (e.g., Doyle \& Aboud, 1995; Doyle et al., 1988). One of the potential problems with such tasks is that children can tailor their responses, particularly where there are social norms against the expression of prejudice. Nesdale argues that the apparent reduction in prejudice across middle childhood is a result of children's increasing awareness of the unacceptability of openly expressing prejudice against outgroups, rather than of prejudice reduction per se. He suggests that alternative measures of children's implicit rather than explicit attitudes are therefore required to test between the two theories. However, evidence from recent studies using implicit measures (e.g., Davis, Leman \& Barrett, 2007; Dunham, Baron \& Banaji, 2006) do not support SIDT, with levels of implicit prejudice either remaining steady after 6-7 years of age or declining rather than increasing after this age. SIDT also has difficulty explaining why, in countries which have experienced inter-ethnic conflict or warfare, extreme negativity can be exhibited towards enemy groups at the age of 2-3 years (Bar-Tal, 1996; Bar-Tal \& Teichman, 2005; Povrzanovi?, 1997).

Social identity theory. Social identity theory (SIT) does not make predictions about agelinked developmental changes in children's attitudes, but it does make predictions about the circumstances under which ingroup bias and outgroup prejudice will occur. SIT was developed by Tajfel (1978; Tajfel \& Turner, 1986), who argued that when individuals internalise a social group membership as part of their self-concept, those individuals are motivated to view that social group in a positive way. In order to do this, the ingroup is compared against outgroups using dimensions of comparison which yield more positive representations of the ingroup than of outgroups. The positive distinctiveness which is ascribed to the ingroup over the outgroups on these chosen dimensions is then used as a source of positive self-esteem. However, SIT postulates that this only occurs under certain conditions. First, the individual must have internalised the social group membership as part of his or her self-concept. If internalisation has not occurred, or if identification with the group is weak, then these effects will not occur. Second, the comparison outgroups must be relevant to the ingroup's own self-definition. If outgroups are not relevant to how the ingroup views itself, then ingroup favouritism and/or outgroup denigration will not occur. Third, the situation in which these social comparisons take place must allow comparisons to be made on dimensions which are relevant for the ingroup's own self-definition.

In addition, Tajfel and Turner (1986) argue that, where an outgroup is perceived to have a clearly superior status to the ingroup, alternative strategies need to be used instead to achieve positive self-esteem. These include leaving the ingroup (individual mobility), redefining the ingroup or changing the dimensions which are being used for the comparison (social creativity), or changing the social structure itself (social competition). Individual mobility may occur when 
group boundaries are viewed as being permeable, while social creativity and social competition may occur when group boundaries are viewed as being impermeable. Social competition is most likely to occur when status differentials are perceived to be illegitimate or the status of the outgroup is perceived to be unstable. Because the strategy depends on perceptions of group boundary permeability and the legitimacy and stability of status differentials, SIT proposes that intergroup attitudes and behaviours vary depending on a wide range of different factors.

More recent research inspired by SIT (e.g., Crocker \& Quinn, 2001; Ellemers \& Barreto, 2001; Ellemers, Spears \& Doosje, 1999; Mummendey, Kessler, Klink \& Mielke, 1999; Simon, 2004) has examined the consequences of belonging to a social group which is perceived to be under threat. This work has revealed that members of threatened groups tend to have higher levels of identification with the ingroup, show higher levels of outgroup prejudice and/or ingroup favouritism, are more sensitive to status differentials between groups, and perceive the ingroup as being more homogeneous and more cohesive. However, these effects only occur among individuals with high levels of ingroup identification; individuals with weak identifications may simply disidentify with the group still further under conditions of theat. Patterns of national identifications and attitudes will therefore differ in relatively peaceful countries where the national group is not perceived to be under threat vs. countries characterised by intergroup conflict, violence or warfare.

SIT can explain why children belonging to different groups display different intergroup attitudes depending on their strength of identification with the ingroup, the perceived status of the ingroup and perceptions of threat. It also helps to explain why attitudes towards outgroups which vary in status are differentiated so that attitudes towards one outgroup may be different from attitudes towards another outgroup.

Societal-social-cognitive-motivational theory. Societal-social-cognitive-motivational theory (SSCMT) has recently been put forward by Barrett (2007, 2009; Barrett \& Davis, 2008). Like SIT, this theory does not make predictions about the particular ages at which ingroup favouritism or outgroup prejudice occur. Instead, this theory attempts to integrate within a single over-arching framework all of the influences which impact on children's intergroup attitudes.

SSCMT is represented diagrammatically in Figure 1. SSCMT starts from the observation that the child always develops within a particular societal niche characterised by specific historical, geographical, economic and political circumstances. These circumstances define the relationships between the child's ingroups and salient outgroups, their status differentials and their history of peaceful co-existence and/or conflict. Adult members of the child's society hold their own beliefs and attitudes concerning these circumstances, and these can drive their behaviours. From the point of view of the developing child, the most relevant individuals here are parents, teachers and the people who produce materials for school curricula, textbooks and the mass media. 


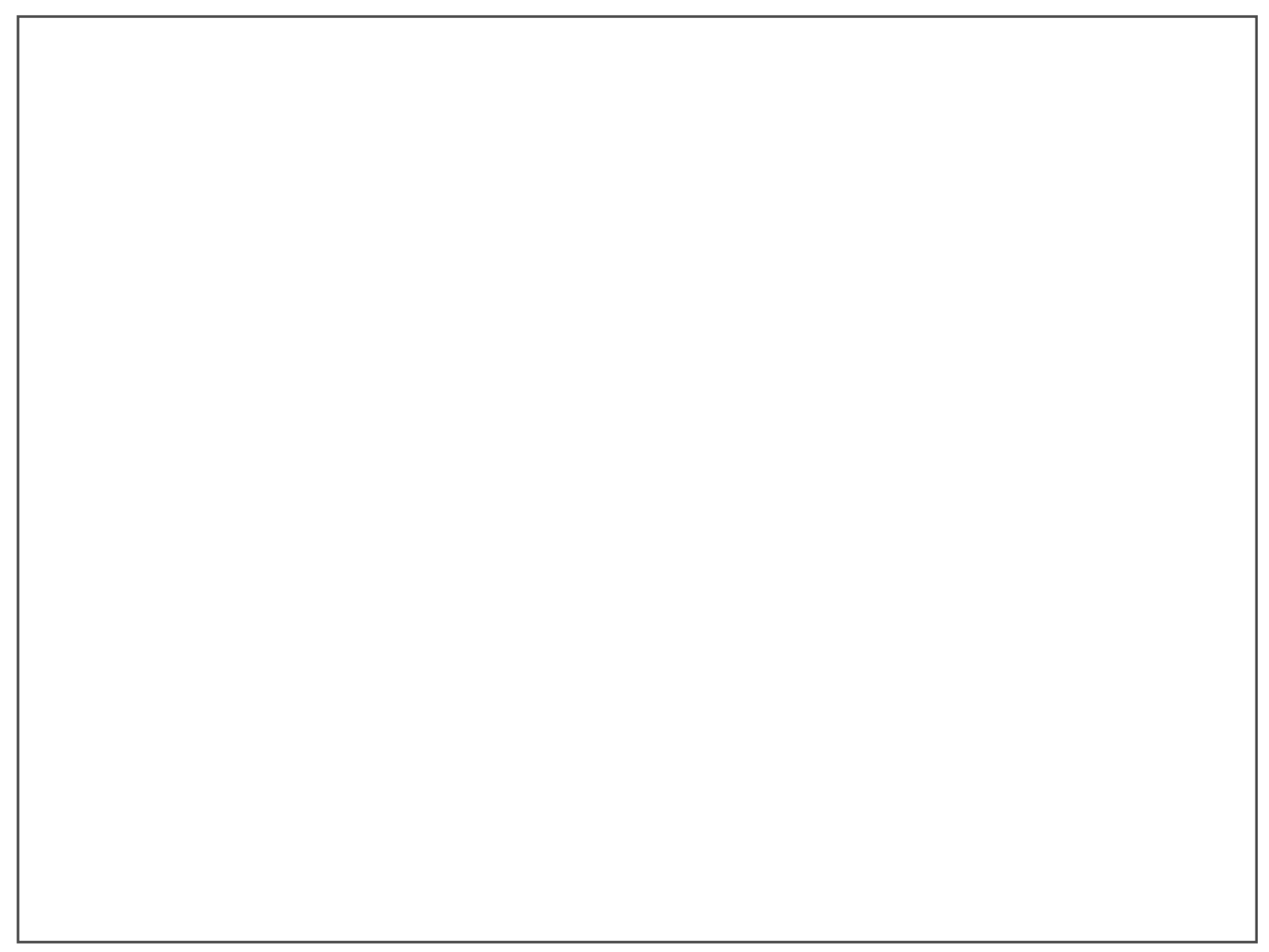


SSCMT proposes that parents' discourse and actions can directly influence their children's developing intergroup attitudes. However, parents can also have indirect effects, because they determine where the family lives, where they go on holiday and the kinship relations of the child (all of which may affect the nature of the child's personal contact with people from other national, ethnic and racial groups). Parents also determine which school the child attends, and hence the educational curriculum, textbooks, teachers and peer group to which the child is exposed. The school itself can also influence the child's personal contact with people from other national, ethnic and racial groups (depending on its own ethnic and racial mix). In addition, parents buy goods for the family home such as books, televisions, computers connected to the Internet, etc. In the case of younger children, parents may also control access to some of these information sources.

Hence, there are many sources of information about other groups available to the child: personal contact with members of those groups, the school curriculum and textbooks, teacher discourse and practices, parental discourse and practices, peer group discourse and practices, and representations of other groups in the mass media (Barrett, 2007; Bar-Tal \& Teichman, 2005; Oppenheimer, in press). However, which information sources are actually attended to by the child are influenced by the child's own perceptual and attentional processes. These in turn are influenced by the child's cognitive, affective and motivational processes (including levels of identification with national, ethnic and racial ingroups). Hence, different sets of environmental factors may be influential for different children depending on their own psychological characteristics. In addition, the child's own discourse and actions may be responded to by parents, teachers, peers, etc., and these actors may either provide further information to the child, challenge what the child has said or done, or punish or praise the child.

SSCMT postulates that different constellations of factors are the primary drivers of intergroup attitudes in different children, depending on their own psychological characteristics, the groups to which they belong, and the particular societal contexts in which they live. In other words, SSCMT proposes that the relative weightings which may be attached to the arrows in Figure 1 vary from one child to another, and from one socio-historical setting to another. Both cognitive development and social identity processes may play important roles, as CDT and SIT suggest, but SSCMT proposes that these factors can be over-ridden in some contexts by other factors such as parental discourse, media representations or educational influences. Hence, SSCMT postulates that there is substantial variability in the development of children's intergroup attitudes depending on the specific contexts in which they live.

Integrative developmental-contextual theory. Integrative developmental-contextual theory (IDCT) has been developed by Bar-Tal and Teichman (2005; Teichman \& Bar-Tal, 2008) to account for the development of children's intergroup attitudes within societal contexts characterised by intractable intergroup conflict. The theory is therefore especially relevant to several of the empirical studies reported in this special issue.

IDCT proposes that when there is serious and ongoing conflict between the ingroup and an outgroup, ingroup members acquire a shared psychological intergroup repertoire (SPIR) in relationship to that outgroup. This repertoire consists of stereotypes of the outgroup, prejudice, associated emotions and behavioural intentions towards the outgroup. The acquisition of a SPIR is influenced by affective states, cognitive development and identity development. While all three factors can potentially operate at all ages, the prevailing social context affects their relative salience. In contexts involving intractable conflict, affective states tend to be the dominant factor in the preschool years, and so, between the ages of 2 and 6, negative affect dominates, resulting in strong negative feelings towards members of the enemy outgroup. Once established, this kind of 
SPIR can then swamp out possible cognitive effects in later childhood. The result is that prejudice against the enemy nation is acquired early (at 2-3 years of age), no reduction in prejudice takes place during middle childhood (7-9 years), and during early adolescence (10 years plus) identity concerns and their motivational correlates may lead to a further increase in hostility towards the enemy outgroup. The content of the SPIR itself is transmitted by socialisation agents, including parents, the mass media and the school.

According to IDCT, once it has been formed, a SPIR will influence the relative salience of affective, cognitive and identity factors, so that the SPIR and these factors reinforce each other, consolidating negative attitudes and prejudice towards the enemy. Extreme ethnocentrism results, which is highly resistant to change. For this reason, attempts at intervention and the amelioration of negative attitudes (e.g. through education) may be ineffective.

Thus, according to IDCT, in societies characterised by intractable conflict, attitudes towards the enemy outgroup develop in a different way from the way in which attitudes to other neutral outgroups develop, and from the way in which intergroup attitudes develop in peaceful societies. Hence, like SIT and SSCMT, IDCT emphasises that the development of intergroup attitudes does not follow a universal trajectory.

Bar-Tal and Teichman (2005; see also Teichman \& Bar-Tal, 2008) provide a wealth of evidence that, in Israel, which is a context characterised by an intractable conflict between Jews and Arabs, Jewish children do indeed exhibit high levels of prejudice towards Arabs at an early age, do not moderate their prejudice across the years of middle childhood, and show a further elevation in this prejudice in early adolescence. These studies also reveal that majority Jewish and minority Arab children in Israel display different patterns of attitude development. Bar-Tal and Teichman argue that the Jewish children's attitudes are driven mainly by Israel's ongoing conflict with its neighbouring states, whereas the Arab children's attitudes are driven primarily by their minority status within Israel.

IDCT and SSCMT clearly have considerable conceptual overlap but different foci, with the former theory providing a specific account of children's development within contexts characterised by intractable intergroup conflict, and the latter theory providing a more general account of the full range of possible factors which may impact on children's development across all types of societal context. Despite this difference in focus, the two theories share several common postulates. For example, both theories emphasise: (i) the absence of universal developmental trajectories and the existence of pervasive variability in the development of intergroup attitudes; (ii) the role of parents, the mass media and education in transmitting representations of prevailing intergroup relations to the child; (iii) the possible influence of cognitive, affective, motivational and identity factors in the development of intergroup attitudes; (iv) the idea that cognitive, affective, motivational and identity factors can affect the uptake of information from the environment; and (v) the idea that different factors and causal pathways may dominate in a child's development depending on the specific societal setting within which that child is living.

\section{The shared methodology used by the studies reported in this special issue}

The present multi-national study was conducted against this empirical and theoretical backdrop. One of the aims of the study was to examine the extent to which the development of children's attitudes to other nations varies across different societal contexts. This comparative aim required identical methodology to be used with all groups of children to permit formal comparisons to be made. The shared methodology which was used included the following 
measures.

Strength of Identification Scale. The Strength of Identification Scale (SoIS) (Barrett, 2007) is a scale which has been developed to measure the strength of national, ethnic, racial or religious identification in children and adolescents. It consists of a short set of questions administered in an interview format to 5- to 11-year-olds (with response options being written on cards and read out to the child) or in a questionnaire format to 11- to 16-year-olds (with rating scales being used instead to capture responses). The full set of six items in the 5- to 11-year-old version of the scale are as follows (where $\mathrm{X}$ represents the targeted identity):

\section{Degree of identification}

Question: Which one of these do you think best describes you?

Response options: very $X$, quite $X$, a little bit $X$, not at all $X$

\section{Pride}

Question: How proud are you of being X?

Response options: very proud, quite proud, a little bit proud, not at all proud

\section{Importance}

Question: How important is it to you that you are X?

Response options: very important, quite important, not very important, not important at all 4. Feeling

Question: How do you feel about being X?

Response options: very happy, quite happy, neutral, quite sad, very sad (administered using a set of five 'smiley' faces)

\section{Negative internalisation}

Question: How you would feel if someone said something bad about X people?

Response options: very happy, quite happy, neutral, quite sad, very sad (administered using a set of five 'smiley' faces)

\section{Positive internalisation}

Question: How you would feel if someone said something good about X people?

Response options: very happy, quite happy, neutral, quite sad, very sad (administered using a set of five 'smiley' faces)

The questions are scored so that low scores represent low levels of identification, and high scores represent high levels of identification. Because the questions use a mixture of 4- and 5point scales, either the item scores are standardised before they are averaged, or the scores on the 4-point scales are rescaled onto 5-point scales before averaging.[2] All six items need not be used, particularly where the wording of a particular question is awkward and/or unnatural for the identity which is being tested.

The SoIS has previously been used to measure the strength of national, ethnic, racial and religious identification in various populations, including national identifications in white English 11- to 16-year-olds (Dixon, 2002; Forrest \& Barrett, 2001), national identifications in 6- to 11year-olds in Scotland and Wales (Penny, Barrett \& Lyons, 2001; Trimby, 2005), national and ethnic identifications in an ethnically mixed group of 11- to 16-year-olds in London (Alexander, 2002), religious identifications in Muslim, Hindu and Christian 5- to 11-year-olds in England (Takriti, 2002), national, ethnic and religious identifications in English, Indian and Pakistani 7- to 11-year-olds (Vethanayagam \& Barrett, 2007), racial and national identifications in 5- to 9-yearold children in England (Davis et al., 2007), national identifications in Iranian 11- to 17-year-olds in England and Iran (Sahlabadi, 2002), national identifications in 12- to 18-year-olds in Germany (Maehr, 2005), and ethnic and religious identifications in Albanian 8- to 13-year-olds in Greece 
(Manouka, 2001). These studies have found that SoIS item scores always load onto a single factor (eigenvalues ranging between 2.02 and 3.30; \% of variance explained ranging between 40.8 and 80.1 ) and scale reliably (Cronbach's alpha ranging between .60 and .91 , with the sole exception of young white children's racial identifications in the study by Davis et al., 2007, where the reliability was only .41). In addition, the test-retest reliability of the SoIS over an eight week period has been found to be .68 (Barrett, 2007).

In the following studies which are reported in this special issue, the 5- to 11-year-old version of the SoIS was used to assess the strength of children's national identifications. In order to control possible order effects, for each child individually, the order of administration of the six questions was randomised. In addition, to avoid possible left-right response biases, response cards were laid out in sequence always keeping the "don't know" card on the far right but reversing the order of layout of the other cards within each set across successive children.

The trait attribution task and the affect questions. Attitudes to ingroups and outgroups were measured using a trait attribution task (taken from Barrett et al., 1997). The task used a set of 12 cards, on each of which one of the following traits was written: clean, dirty, friendly, unfriendly, smart, stupid, hard working, lazy, happy, sad, honest and dishonest. The cards were randomly ordered for each individual child. The pile of cards was shown to the child so that he or she could see the word on the first card, and the following instructions were given: Here are some cards with words on them that describe people. So, we can say that some people are (word on first card). (First card removed, and child shown the second card.) And some people are (word on second card). (Second card removed.) And some people are (word on third card). Right? Now, what I want you to do is to go through all these words one by one, and I want you to sort out those words which you think can be used to describe X people (where $\mathrm{X}$ represented the name of the target national group). Can you do that for me please? (Child given the complete set of cards.) Sort out the words which you think describe X people. When the child had finished the task, the cards were gathered up in a randomly ordered pile, ready for testing the next target nationality. The child was then asked two further questions to assess general affect towards the target group of people: Now, I just want to ask you one more thing about $X$ people. Do you like or dislike $X$ people? If the child said that he or she liked or disliked them, the second question was then given: How much? Do you like/dislike them a lot or a little?

At the end of this sequence of questions, the child was told: Right now, let's do the same thing again, but this time thinking about $X$ people (where $\mathrm{X}$ was the name of the next target group to be tested). Can you sort out for me those words which you think can be used to describe $X$ people? In total, the children in the present sequence of studies were given the above task and questions in relationship to their own national ingroup, an outgroup which was a 'traditional enemy' of their own ingroup, plus two relatively neutral outgroups. The order in which the four target national groups were tested was randomised for each individual child.

The wordings used in the trait attribution task and the affect questions have been found to work well with children in a range of different national settings (Bennett, Lyons, Sani \& Barrett, 1998; Vila, del Valle, Perera, Monreal \& Barrett, 1998; Castelli, Cadinu \& Barrett, 2002; Giménez, Canto, Fernández \& Barrett, 2003; Bennett et al., 2004; Reizábal, Valencia \& Barrett, 2004). The quantitative scores which were derived from the trait attribution task included the total number of positive traits and the total number of negative traits attributed to each individual target group. In addition, by subtracting the number of negative traits from the number of positive traits, an overall positivity score was derived for each target group. The responses to the affect questions were scored on a 5-point Likert scale ranging from like a lot (5) to dislike a lot (1) with neutral 
responses being scored at the midpoint (3).

\section{Procedure}

The above tasks were administered to the children as follows. Each child was interviewed individually in a quiet room in their school. After establishing rapport, it was explained that the interviewer was interested in what they thought about certain things and that the child would be asked to complete some tasks and answer some questions. Each child was reassured that they were not being tested, that there were no good or bad answers, and that no one other than the interviewer would know what they had said. The children were then asked to give their age, gender, and ethnicity. Their responses to these initial questions, as well as their responses on all the tasks, were recorded on individual response sheets.

Because the research took place in different languages, backtranslation procedures were used. The initial draft of the tasks was drawn up in the English language, and this draft was translated into the target language by one translator, and then backtranslated into English by a different translator. The product was compared with the original English version to ascertain whether any changes in meaning had occurred. If they had, the translators discussed the change in meaning and agreed on an appropriate translation in the target language.

\section{Conclusion}

In this paper, we have provided a brief overview of some of the previous research findings in this field and of the five principal theories which may be applied to explain developmental phenomena in this domain. These overviews should enable the reader to locate the following papers in this special issue within their broader research context. In this paper, we have also described the measures and procedures which were used in the studies reported in the following papers. These papers report and interpret the findings obtained in the following countries: England, Bosnia, Northern Ireland, northern Cyprus, southern Cyprus, and the Basque Country. The sequence of papers ends with a final paper reporting the findings of the cross-national comparative analyses, which also incorporate the data collected in The Netherlands and Israel. 


\section{References}

Aboud, F.E. (1988). Children and Prejudice. Oxford: Blackwell.

Aboud, F.E. (2008). A social-cognitive developmental theory of prejudice. In In S.M. Quintana \& C. McKown (Eds.), The Handbook of Race, Racism and the Developing Child (pp. 55-71). Hoboken, NJ: John Wiley \& Sons.

Aboud, F.E. \& Amato, M. (2001). Developmental and socialization influences on intergroup bias. In R. Brown \& S.L. Gaertner (Eds.), Blackwell Handbook of Social Psychology: Intergroup Processes (pp. 65-85). Oxford: Blackwell.

Alexander, E. (2002). National and ethnic identity in British adolescents. Unpublished BSc dissertation, University of Surrey.

Apple, M. (1993). Official Knowledge: Democratic Education in a Conservative Age. London: Routledge.

Axia, G., Bremner, J.G., Deluca, P. \& Andreasen, G. (1998). Children drawing Europe: The effects of nationality, age and teaching. British Journal of Developmental Psychology, 16, 423-437.

Barrett, M. (1996). English children's acquisition of a European identity. In G. Breakwell \& E. Lyons (Eds.), Changing European Identities: Social Psychological Analyses of Social Change (pp. 349-369). Oxford: Butterworth-Heinemann.

Barrett, M. (2005a). Children's understanding of, and feelings about, countries and national groups. In M. Barrett \& E. Buchanan-Barrow (Eds.), Children's Understanding of Society (pp. 251-285). Hove: Psychology Press.

Barrett, M. (2005b). National identities in children and young people. In S. Ding \& K. Littleton (Eds.), Children's Personal and Social Development (pp. 181-220). Milton Keynes: The Open University/Blackwell Publishing.

Barrett, M. (2007). Children's Knowledge, Beliefs and Feelings about Nations and National Groups. Hove: Psychology Press.

Barrett, M. (2009). The development of children's intergroup attitudes. In A. Hu \& M. Byram (Eds.), Interkulturelle Kompetenz und Fremdsprachliches Lernen: Modelle, Empirie, Evaluation/Intercultural Competence and Foreign Language Learning: Models, Empiricism, Assessment (pp. 69-86). Tübingen, Germany: Gunter Narr Verlag.

Barrett, M. \& Davis, S.C. (2008). Applying social identity and self-categorization theories to children's racial, ethnic, national and state identifications and attitudes. In S.M. Quintana \& C. McKown (Eds.), The Handbook of Race, Racism and the Developing Child (pp. 72-110). Hoboken, NJ: John Wiley \& Sons.

Barrett, M., Lyons, E., Bennett, M., Vila, I., Giménez, A., Arcuri, L. \& de Rosa, A.S. (1997). Children's Beliefs and Feelings about Their Own and Other National Groups in Europe. Final Report to the Commission of the European Communities, Directorate-General XII for Science, Research and Development, Human Capital and Mobility (HCM) Programme, Research Network No. CHRX-CT94-0687.

Barrett, M., Lyons, E. \& del Valle, A. (2004). The development of national identity and social identity processes: Do social identity theory and self-categorization theory provide useful heuristic frameworks for developmental research? In M. Bennett \& F. Sani (Eds.), The Development of the Social Self (pp. 159-188). Hove, UK: Psychology Press.

Barrett, M. \& Short, J. (1992). Images of European people in a group of 5-10 year old English school children. British Journal of Developmental Psychology, 10, 339-363. 
Barrett, M., Wilson, H. \& Lyons, E. (2003). The development of national in-group bias: English children's attributions of characteristics to English, American and German people. British Journal of Developmental Psychology, 21, 193-220.

Bar-Tal, D. (1996). Development of social categories and stereotypes in early childhood: The case of "the Arab" concept formation, stereotype and attitudes by Jewish children in Israel. International Journal of Intercultural Relations, 20, 341-370.

Bar-Tal, D. (1997). Formation and change of ethnic and national stereotypes: An integrative model. International Journal of Intercultural Relations, 21, 491-523.

Bar-Tal, D. \& Teichman, Y. (2005). Stereotypes and Prejudice in Conflict: Representations of Arabs in Israeli Jewish Society. Cambridge: Cambridge University Press.

Bennett, M., Barrett, M., Karakozov, R., Kipiani, G., Lyons, E., Pavlenko, V. \& Riazanova, T. (2004). Young children's evaluations of the ingroup and of outgroups: A multi-national study. Social Development, 13, 124-141.

Bennett, M., Lyons, E., Sani, F. \& Barrett, M. (1998). Children's subjective identification with the group and ingroup favoritism. Developmental Psychology, 34, 902-909.

Bourchier, A., Barrett, M. \& Lyons, E. (2002). The predictors of children's geographical knowledge of other countries. Journal of Environmental Psychology, 22, 79-94.

Castelli, L., Cadinu, M. \& Barrett, M. (2002). Lo sviluppo degli atteggiamenti nazionali in soggetti in età scolare. Rassegna di Psicologia, 19, 49-65.

Crocker, J. \& Quinn, D.M. (2001). Psychological consequences of devalued identities. In R. Brown \& S.L. Gaertner (Eds.), Blackwell Handbook of Social Psychology: Intergroup Processes (pp. 238-257). Oxford: Blackwell.

Davis, S.C., Leman, P.J. \& Barrett, M. (2007). Children's implicit and explicit ethnic group attitudes, ethnic group identification, and self-esteem. International Journal of Behavioral Development, 31, 514-525.

Dixon, A. (2002). Social identity theory and the development of national identity in British adolescents. Unpublished BSc dissertation, University of Surrey.

Doyle, A.B. \& Aboud, F.E. (1995). A longitudinal study of white children's racial prejudice as a social-cognitive development. Merrill-Palmer Quarterly, 41, 209-228.

Doyle, A.B., Beaudet, J. \& Aboud, F.E. (1988). Developmental patterns in the flexibility of children's ethnic attitudes. Journal of Cross-Cultural Psychology, 19, 3-18.

Dunham, Y., Baron, A.S. \& Banaji, M.R. (2006). From American city to Japanese village: A cross-cultural investigation of implicit race attitudes. Child Development, 77, 1268-1281.

Ellemers, N. \& Barreto, M. (2001). The impact of relative group status: affective, perceptual and behavioral consequences. In R. Brown \& S.L. Gaertner (Eds.), Blackwell Handbook of Social Psychology: Intergroup Processes (pp. 324-343). Oxford: Blackwell.

Ellemers, N., Spears, R. \& Doosje, B. (Eds.) (1999). Social Identity. Oxford: Blackwell.

Forrest, L. \& Barrett, M. (2001). English adolescents' sense of national identity, identity motivations and national historical icons. Unpublished paper, Department of Psychology, University of Surrey.

Giménez, A., Canto, J.M., Fernández, P. \& Barrett, M. (2003). Stereotype development in Andalusian children. The Spanish Journal of Psychology, 6, 28-34.

Gould, P. \& White, R. (1986). Mental Maps (2nd edition). Boston: Allen \& Unwin.

Helwig, C.C. \& Prencipe, A. (1999). Children's judgments of flags and flag-burning. Child Development, 70, 132-143.

Hess, R.D., \& Torney, J.V. (1967). The Development of Political Attitudes in Children. Chicago: 
Aldine.

Holloway, S.L. \& Valentine, G. (2000). Corked hats and Coronation Street: British and New Zealand children's imaginative geographies of the other. Childhood, 7, 335-357.

Jahoda, G. (1962). Development of Scottish children's ideas and attitudes about other countries. Journal of Social Psychology, 58, 91-108.

Jahoda, G. (1963a). The development of children's ideas about country and nationality, Part I: The conceptual framework. British Journal of Educational Psychology, 33, 47-60.

Jahoda, G. (1963b). The development of children's ideas about country and nationality, Part II: National symbols and themes. British Journal of Educational Psychology, 33, 143-153.

Jaspers, J.M.F., van de Geer, J.P., Tajfel, H. \& Johnson, N. (1972). On the development of national attitudes in children. European Journal of Social Psychology, 2, 347-369.

Johnson, N., Middleton, M. \& Tajfel, H. (1970). The relationship between children's preferences for and knowledge about other nations. British Journal of Social and Clinical Psychology, 9, 232-240.

Lambert, W.E. \& Klineberg, O. (1967). Children's Views of Foreign Peoples: A Cross-National Study. New York: Appleton-Century-Crofts.

Maehr, S. (2005). "How can one be proud? I am not a Nazi!": An investigation of German pupils' sense of national identity and knowledge of national symbols. Unpublished BSc dissertation, University of Surrey.

Manouka, A. (2001). Self-concept and ethnic identity of Albanian children who have emigrated in Greece. Unpublished MSc dissertation, University of Surrey.

Middleton, M., Tajfel, H. \& Johnson, N. (1970). Cognitive and affective aspects of children's national attitudes. British Journal of Social and Clinical Psychology, 9, 122-134.

Moodie, M.A. (1980). The development of national identity in white South African schoolchildren. Journal of Social Psychology, 111, 169-180.

Moore, S.W., Lare, J. \& Wagner, K.A. (1985). The Child's Political World: A Longitudinal Perspective. New York: Praeger.

Mummendey, A., Kessler, T., Klink, A. \& Mielke, R. (1999). Strategies to cope with negative social identity: Predictions by social identity theory and relative deprivation theory. Journal of Personality and Social Psychology, 76, 229-245.

Nesdale, D. (2004). Social identity processes and children's ethnic prejudice. In M. Bennett \& F. Sani (Eds.), The Development of the Social Self (pp. 219-245). Hove, UK: Psychology Press.

Nesdale, D. (2008). Social identity development and children's ethnic attitudes in Australia. In S.M. Quintana \& C. McKown (Eds.), The Handbook of Race, Racism and the Developing Child (pp. 313-338). Hoboken, NJ: John Wiley \& Sons.

Oppenheimer, L. (2005). The development of enemy images: Measurement and initial findings. British Journal of Developmental Psychology, 23, 645-660.

Oppenheimer, L. (2006). The development of enemy images: A theoretical contribution. Peace and Conflict: Journal of Peace Psychology. 12, 269-292.

Oppenheimer, L. (in press). Are children's views of the "enemy" shaped by a highly publicized negative event? International Journal of Behavioral Development.

Oppenheimer, L., \& Hakvoort, I. (2003). Will the Germans ever be forgiven? Memories of the Second World War generations later. In E. Cairns and M. D. Roe (Eds.), The role of Memory in ethnic conflict (pp. 94-104). Houndmills, Basingstoke, UK: Palgrave-Macmillan

Penny, R., Barrett, M. \& Lyons, E. (2001). Children's naïve theories of nationality: a study of Scottish and English children's national inclusion criteria. Poster presented at the 
$10^{\text {th }}$ European Conference on Developmental Psychology, Uppsala University, Uppsala, Sweden, August 2001.

Piaget, J. \& Weil, A.M. (1951). The development in children of the idea of the homeland and of relations to other countries. International Social Science Journal, 3, 561-578.

Povrzanovi?, M. (1997). Children, war and nation: Croatia 1991-4. Childhood: A Global Journal of Child Research, 4, 81-102.

Reizábal, L., Valencia, J. \& Barrett, M. (2004). National identifications and attitudes to national ingroups and outgroups amongst children living in the Basque Country. Infant and Child Development, 13, 1-20.

Sahlabadi, M. (2002). The strength of national identity, identity motivations and beliefs about war of Iranian adolescents raised in England and Iran. Unpublished BSc dissertation, University of Surrey.

Schleicher, K. \& Kozma, T. (Eds.) (1992). Ethnocentrism in Education. Frankfurt: Peter Lang.

Simon, B. (2004). Identity in Modern Society: A Social-Psychological Perspective. Oxford: Blackwell Publishing.

Tajfel, H. (1978). Social categorization, social identity and social comparison. In H. Tajfel (Ed.), Differentiation between Social Groups: Studies in the Social Psychology of Intergroup Relations (pp. 61-76). London: Academic Press.

Tajfel, H., Jahoda, G., Nemeth, C., Rim, Y. \& Johnson, N. (1972). The devaluation by children of their own national and ethnic group: Two case studies. British Journal of Social and Clinical Psychology, 11, 235-243.

Tajfel, H. \& Turner, J.C. (1986). The social identity theory of intergroup behaviour. In S. Worchel \& W.G. Austin (Eds.), Psychology of Intergroup Relations, $2^{\text {nd }}$ edition (pp. 7-24). Chicago: Nelson-Hall.

Takriti, R. (2002). The Development of Religious Identity in Christian, Hindu and Muslim Children. Unpublished $\mathrm{PhD}$ thesis, University of Surrey.

Teichman, Y. (2001). The development of Israeli children's images of Jews and Arabs and their expression in human figure drawings. Developmental Psychology, 37, 749-761.

Teichman, Y.\& Bar-Tal, D. (2008). Acquisition and development of a shared psychological intergroup repertoire in a context of an intractable conflict. In S.M. Quintana \& C. McKown (Eds.), The Handbook of Race, Racism and the Developing Child (pp. 452-482). Hoboken, NJ: John Wiley \& Sons.

Trimby, H. (2005). The development of Welsh children's sense of national identity. Unpublished BSc dissertation, University of Surrey.

Vethanayagam, S. \& Barrett, M. (2007). English, Indian and Pakistani children's national, ethnic and religious identifications. Poster presented at the Annual Conference of the Social Psychology Section of the British Psychological Society, University of Kent, September 2007.

Vila, I., del Valle, A., Perera, S., Monreal, P. \& Barrett, M. (1998). Autocategorizacion, identidad nacional y contexto linguistico. Estudios de Psicologia, 60, 3-14.

Weinstein, E.A. (1957). Development of the concept of flag and the sense of national identity. Child Development, 28, 167-174.

Wiegand, P. (1991a). The 'known world' of primary school children. Geography, 76, 143-149.

Wiegand, P. (1991b). Does travel broaden the mind? Education, 3, 54-58. 
[1] In this special issue, the data collected in The Netherlands and in Israel are not reported separately in individual papers. However, these data are included in the cross-national comparative analyses reported in the final paper by Oppenheimer.

[2] In rescaling, $1=1,2=2.33,3=3.66$ and $4=5$. 